\title{
In the Long Run, the Multiplier is Dead: Lessons from a Simulation
}

\author{
Ross Guest and Anthony J. Makin ${ }^{1}$
}

\section{Abstract}

This paper re-examines the significance of the fiscal multiplier from an intertemporal perspective using simulation results derived from a standard overlappinggenerations framework. It reveals that even if fiscal stimulus in the form of extra public consumption spending is assumed to increased output and employment in the short run, the negative medium to long-term consequences of the stimulus will ultimately exceed, in present-value terms, the short-term macroeconomic benefits of that stimulus. This is due to the interest rate and tax effects of the stimulus-induced budget deficit which lowers future private investment, household consumption, and labour supply.

\section{Introduction}

Under the auspices of the G20 group of economies, Australia enthusiastically participated in the largest internationally co-ordinated fiscal expansion the world has ever seen to offset the predicted recessionary impact of the 2008-09 global financial crisis (GFC). Yet, despite the globally co-ordinated response, a case can be made that fiscal stimulus, especially the emphasis on unproductive government spending rather than tax cuts, was unnecessary for Australia. Interest rates remained significantly above the zero bound, so further relaxation of monetary policy remained an option. Moreover, the trade-weighted exchange rate had depreciated by nearly 30 per cent, boosting competitiveness and net exports (Makin 2010).

Nevertheless, if interest rates are low or zero, the enduring appeal of fiscal stimulus is that it seemingly provides policymakers with a costless economic solution for counteracting recession and unemployment. However, this Keynesian perspective neglects that boosting aggregate spending to expand output expansion has harmful future macroeconomic consequences due to the budget deficits and higher public debt that arise.

$1 \quad$ Griffith University; r.guest@griffith.edu.au 
Fiscal multipliers have been estimated for different countries and for different fiscal instruments using general equilibrium models and econometric approaches (see, for instance, Blanchard and Perotti 2002; Cogan et al. 2010; and Formi et al. 2009). These estimates vary considerably, prompting Auerbach et al. (2010) to comment in a recent survey of multiplier estimates that the range is 'almost embarrassingly large'. Most are positive because they are either based on Keynesian assumptions or, in the case of general equilibrium models, are derived by setting interest rates low with little, if any, regard to longer-run public-debt related implications. ${ }^{2}$

When gauging the size of fiscal multiplier, a key issue is the time frame over which the macroeconomic effects are estimated. If a fiscal multiplier happens to be positive in the short run, but negative over a longer time interval, then from an inter-temporal perspective fiscal 'stimulus' is a deceptive term. The main focus of this contribution is to examine the size of the fiscal multiplier for an economy like Australia over both the short and long term. To do this it refers to a simulation model which uses parameter values adopted by Treasury, but which also explicitly allows for longer-run interest rate, tax, and wage effects stemming from fiscal expansion and the associated budget deficit.

In preview, for the purposes of argument we accept the Keynesian premise that extra spending leads to increased output in the short run. However, after allowing for reasonable interest rate and tax effects, the negative longer-run consequences of fiscal stimulus soon begin to outweigh short-term macroeconomic benefits. The upshot is that the sum of the discounted changes in employment and GDP are negative in the long run. In other words, we show that, even if it has a positive short-run impact, in the long run the fiscal multiplier is dead.

\section{The simulation model ${ }^{3}$}

The key assumptions of the model are as follows. A representative firm produces output of a single tradable good ${ }^{4}$ according to a Cobb-Douglas production function.

The usual first-order conditions determine the capital stock and the wage rate for a unit of aggregate labour, and both competitive factor markets and goods

\footnotetext{
2 The floating exchange rate Mundell-Fleming model and full Ricardian equivalence imply zero fiscal multipliers, whereas the loanable-funds approach and alternative theoretical models - as proposed by Coleman (2010) and Makin(2007), for instance — imply negative multipliers.

3 For further details of the simulation model, see the discussion paper, Guest and Makin (2011, forthcoming), available at http://www.griffith.edu.au/business-commerce/griffith-business-school/departments/ department-accounting-finance-economics/publications/discussion-paper-series-in-economics-and-businessstatistics

4 Hence there is no real exchange rate.
} 
markets clear. In this neoclassical set up, unemployment is implicitly ruled out. However, it is assumed that fiscal stimulus provides a short-run boost to employment (and therefore GDP) by increasing both labour supply and labour demand at the going wage rate. This is an expedient in order to focus on the longer-run effects of fiscal stimulus through its effect on the interest rate, taxes and the real wage.

It is assumed that capital is imperfectly mobile, in the sense that the interest rate is subject to a sovereign risk premium, whereby the interest rate, $r j$, is a function of the ratio of public debt to GDP $(D / Y)$, lagged one period:

$$
r_{j}=\bar{r}+\lambda\left(\frac{D}{Y}\right)_{j-1}
$$

For further details, including all parameter values, see the full working paper: Guest and Makin (2011, forthcoming). One-person households consume both the single good and leisure. A household is formed at age 15 and therefore household consumption includes the consumption of children under age 15. A period of time is one-year duration and a new generation of households is born each period. Each household commences working at age 15, retires at age 70 and dies on their eighty-fifth birthday with certainty. Hence there are overlapping generations of working households alive at any time. They commence working life with zero financial assets and have a target financial wealth of zero at death. They pay the same constant tax rate on income from both capital and labour (discussed below).

Households derive utility from consuming private goods, $C$, and leisure, $S$. Government consumption is assumed to provide no direct utility and hence has no effect on the household's optimal lifetime plan. Households maximise the following lifetime utility function:

$$
U=\sum_{i=1}^{h} \frac{M_{i}^{1-\beta}}{1-\beta}(1+\theta)^{1-i}
$$

subject to a lifetime budget constraint, where $M i$ is a CES index of consumption and leisure, ${ }^{5} \theta$ is the pure time preference rate and $\beta$ is the elasticity of marginal utility. For simplicity, there are no bequests, and total transfer payments paid

5 The elasticity of substitution between $C$ and $S$ takes the value of 1.2. The results are not qualitatively sensitive to the value of this parameter. The value of $\beta$ is 2.0 and the value of theta is 0.03 . 
by the government in a given period are allocated evenly across all households alive in that period, rather than being allocated to certain generations. A single tax rate applies to income from both labour and financial assets.

Households know the parameter values with certainty, but the policy shock comes as a surprise. When the unanticipated fiscal stimulus occurs, households will be at various stages of their lifetime plans - young households will be nearer to the start than older households. At this point, they revise their plans for the remainder of their lifetimes.

The government starts with a balanced budget before the unexpected fiscal stimulus shock arrives, after which agents adjust their plans in response to the shock. The fiscal shock is an increase in government consumption expenditure of, in the base case, 2 per cent of GDP over each of $\mathrm{N}=2$ years. From $j=N+1$, government expenditure returns to its pre-shock level and the government begins to repay its debt by increasing the tax rate until the debt-to-GDP ratio returns to its pre-shock level. In order to avoid an initial jump in the tax rate, the tax rate is assumed to gradually increase for an initial period $j=N+1, \ldots, 2 N$ following the shock.

Following Uhlig (2010), ${ }^{6}$ the dynamic fiscal multiplier at time $t$ is calculated as the discounted sum of the changes in output from $j=1$ (representing the year 2009 when the stimulus is assumed to commence) to $t$, divided by the discounted sum of the stimulus spending, $G$, from $j=1$ to $t$ :

$$
U=\sum_{i=1}^{h} \frac{M_{i}^{1-\beta}}{1-\beta}(1+\theta)^{1-i}
$$

The short-run boost to employment and GDP from stimulus in the form of government consumption expenditure is achieved by assuming a contemporaneous employment multiplier of 0.5 . This is done by simply inflating the level of employment that exists at the time of the shock by half the percentage increase in stimulus spending. That is, given stimulus spending of 2 per cent, the contemporaneous boost in employment is 1 per cent. This extra employment creates output and, therefore, income for consumers, which in turn creates both consumption and tax revenue for government. The employment multiplier of 0.5 is consistent with empirical estimates (OECD 2009; Australian Treasury 2009).

\footnotetext{
6 The main differences are that Uhlig (i) uses a Ramsey model, rather than an OLG model which allows for an intergenerational welfare analysis; and (ii) assumes that government spending and output follow stochastic processes, whereas they are deterministic here.
} 


\section{Results of simulations}

The results are illustrated in Figures 1 and 2 for the base case (sensitivity simulations are briefly discussed below and further details are available in the extended version of the paper). ${ }^{7}$
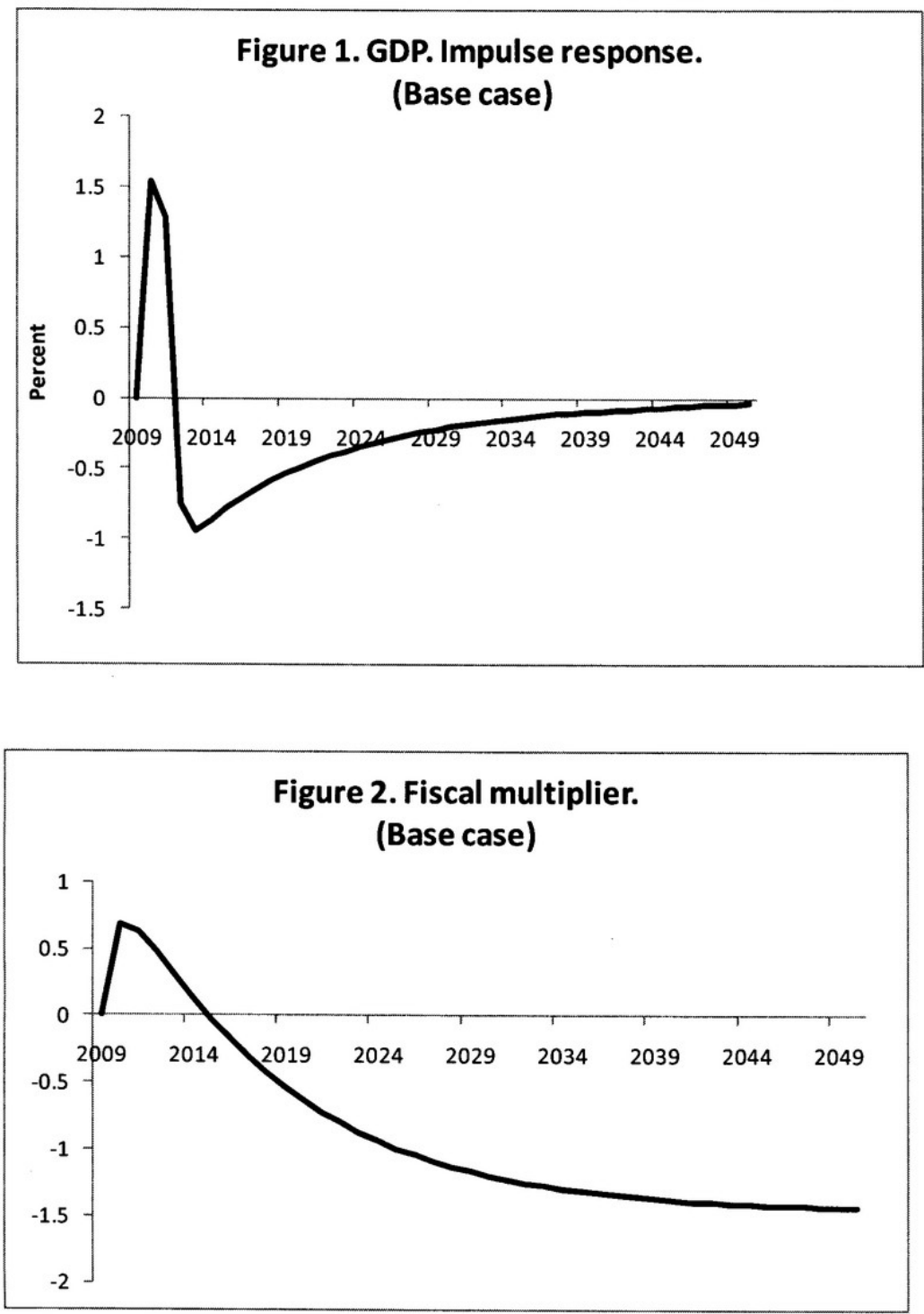

7 Available at: http://www.griffith.edu.au/business-commerce/griffith-business-school/departments/ department-accounting-finance-economics/publications/discussion-paper-series-in-economics-and-businessstatistics 
Figure 1 shows the impulse response to the stimulus, defined as the percentage change in GDP from the pre-stimulus level. Figure 2 shows the dynamic fiscal multiplier. The fiscal stimulus of 2 per cent of GDP boosts GDP by 1.5 percent. This implies a first-year fiscal multiplier ${ }^{8}$ of 0.75 . By the third year, when the stimulus has ceased and taxes start to rise, the GDP response becomes negative. The fiscal multiplier remains positive for several years even though the GDP response has turned negative, because the multiplier is calculated as the cumulative discounted GDP response divided by the cumulative discounted stimulus spending (equation 3).

The initial boost to GDP diminishes almost immediately for a combination of several factors. First the interest rate starts to rise due to the increase in government debt, which lowers investment and, to a less extent, consumption. Second, following the stimulus the tax rate rises in order to start paying off the debt. This reduces the price of leisure, which lowers labour supply. Third, the lower price of leisure is compounded via a lower pre-tax real wage as a result of the lower capital-labour ratio, further reducing the supply of labour. As the debt is eventually paid off, the tax rate and the interest rate return to their original levels and hence so does GDP. This process takes several decades to complete. The fiscal multiplier turns negative after five years in the base case and reaches -1.43 by 2050 . The figure of -1.43 means that the long-run discounted decrease in output is 1.43 times the magnitude of the stimulus spending. These values are consistent with the simulation results in Uhlig (2010) who finds multipliers generally less than 1.0 in the short run and negative in the long run. Uhlig's conclusion, supported here, is that although fiscal stimulus may dampen the severity of a recession in the short run it may extend the duration of the recession for a considerable period.

A number of sensitivity simulations were conducted by varying, within a plausible range, values of the following parameters: the proportion of consumption determined by the rule of thumb; the type of stimulus government consumption spending or transfer payments; the duration of the stimulus after which the spending drops back to its original level; the employment multiplier; and the speed of adjustment of the tax rate and/or spending following the period of stimulus. The qualitative results found in the base case remained intact: the fiscal multiplier eventually became negative in all cases.

A couple of points about the sensitivity simulations are worth noting. The results are quite sensitive to the interest-rate response to size of public debt. The base case assumed that a 10 per cent rise in the debt-to-GDP ratio resulted in a 30 basis

8 The fiscal multiplier is the percentage change in GDP divided by the percentage change in government expenditure. 
point increase in the interest rate (supported by empirical estimates), compared with 10 basis points in the sensitivity simulation. The effect the smaller interestrate response was a larger fiscal multiplier. The long-run multiplier was still negative but of a smaller magnitude: -0.27 , compared with - 1.4 in the base case. Another noteworthy simulation adopted a sharper increase in the tax rate in order to pay back the debt more rapidly. In particular, for the first four years after the stimulus has ended, the tax rate increases on average by 0.7 per cent of GDP, compared with 0.4 per cent in the base case. This had a positive impact on the long-run fiscal multiplier - the long-run value was still negative but only half the negative value in the base case $(-0.7$ compared with -1.4$)$. This shows the long-run benefits of a short period of tighter fiscal policy in unwinding the stimulus.

The dynamic multipliers reported here support the findings in Uhlig (2010) that the positive benefits of fiscal stimulus are short lived. The fiscal multiplier becomes negative in all simulations after 10 years from the time the stimulus was introduced. This qualitative conclusion is robust to a range of assumptions, although the magnitude of the multiplier depends on the size and duration of the stimulus, the degree to which it pushes up interest rates, the rate at which it is unwound and whether it is unwound by tax rises or spending cuts.

Nonetheless, this simulation approach is likely to understate the true longerterm costs of fiscal stimulus and overstate the time it takes for the multiplier to become negative because fiscal activism also undermines business confidence, the effects of which are not explicitly modelled. The oft-proposed Keynesian idea that fiscal stimulus is needed to sustain business confidence contains a contradiction. The contradiction is that the higher-than-necessary interest rates and taxes that result from fiscal expansion must also harm business confidence. This limits asset price recovery, further hampering private investment and the quality of economic growth in the long run.

Prior to the GFC, it was generally accepted that monetary policy (via both interest-rate and exchange-rate effects) influenced the economy in the short run more effectively than fiscal policy. This was because monetary policy was less compromised by recognition, decision and implementation lags, from which the simulation exercise also abstracts. However, the implementation lag (in particular) significantly marred the delivery of Australia's fiscal response to the GFC, as the government sector's direct contribution to boosting domestic consumption and investment was minimal at the height of the GFC impact, and peaked well after it was supposed to according to actual national accounts data (Makin 2010). 


\section{Conclusion}

This contribution highlights numerous mechanisms that have been overlooked or underestimated by advocates of fiscal stimulus with reference to simulation results derived from a standard inter-temporal macroeconomic model. As with any modelling, these results reflect starting assumptions, some of which, if varied, would undoubtedly yield different, more Keynesian-friendly, outcomes. For instance, in this exercise the stimulus is restricted to government consumption expenditure only. This implies there is no accelerator effect which could arise if the public spending boost was assumed to be productive investment expenditure rather than consumption.

In the model, the exogenous short-run boost to GDP and employment is assumed to end when the stimulus ends. Alternatively, introducing a short-run Keynesian effect into the model could have been achieved by introducing wage rigidities in the adjustment process. The justification for assuming that output and employment are exogenously and temporarily boosted by fiscal stimulus in the short run is that it provides a means for examining the medium to longrun offsetting effects of the budgetary consequences of fiscal stimulus. These adverse inter-temporal effects have been largely neglected in current debate.

Specifically, it is important to highlight that following fiscal stimulus, higher interest rates lower future investment and, to a lesser extent, consumption, consistent with the prediction of the short-run Keynesian IS-LM model. Additionally, fiscal stimulus negatively affects post-stimulus output and employment outcomes because it leads to reduced labour supply that arises from higher taxes, as well as from lower pre-tax real wages courtesy of a lower capital-labour ratio.

\section{References}

Australian Treasury 2009, Briefing Paper to Senate Inquiry Into the Government's Economic Stimulus Initiatives, Commonwealth of Australia, Canberra, November. Available at: http://www.aph.gov.au/senate/committee/ economics

Auerbach, A., Gale, W. and Harris, B. 2010, 'Activist Fiscal Policy', Journal of Economic Perspectives 24(4): 141-64.

Blanchard, O. and Perotti R. 2002, 'An Empirical Characterization of the Dynamic Effects of Changes in Government Deficit and Taxes on Output', Quarterly Journal of Economics 117(4): 1329-68. 
Cogan, J., Cwik, T., Taylor, J. and Wieland, V. 2010, 'New Keynesian versus Old Keynesian Multipliers', Journal of Economic Dynamics and Control 34(3): 281-95.

Coleman, W. 2010, 'When Expansionary Fiscal Policy is Contractionary: A Neoklassical Scenario', Economic Record 86 (September): 61-8.

Forni, L., Monteforte, L. and Sessa, L. 2009, 'The General Equilibrium Effects of Fiscal Policy: Estimates for the Euro Area', Journal of Public Economics 93(3): 559-85.

Gale, W. and Oszag, P. 2003, 'Economic Effects of Sustained Fiscal Deficits', National Tax Journal 56: 463-85.

Gale, W. and Oszag, P. 2004, 'Budget Deficits, National Saving and Interest Rates', Brookings Papers on Economic Activity 2: 101-87.

Guest, R. and Makin, A. 2011 (forthcoming), 'Fiscal Stimulus: an Overlapping Generations Analysis', Discussion Paper in Economics, Griffith Business School. Available at: http://www.griffith.edu.au/business-commerce/griffithbusiness-school/departments/department-accounting-finance-economics/ publications/discussion-paper-series-in-economics-and-business-statistics

International Monetary Fund 2010, World Economic Outlook, Chapter 3, International Monetary Fund, Washington.

Makin, A. 2007, 'Re-Examining the Effectiveness of Stabilisation Policy', Australian Economic Papers 46(4): 348-59.

Makin, A. 2010, 'Did Fiscal Stimulus Counter Recession? Evidence from the National Accounts', Agenda 17(2): 5-16.

Organisation for Economic Co-operation and Development 2009, Economic Outlook, Chapter 3 'The Effectiveness and Scope of Fiscal Stimulus', Organisation for Economic Co-operation and Development, Paris.

Uhlig, H. 2010, 'Some Fiscal Calculus', American Economic Review. Papers and Proceedings (May): 30-4. 